\title{
Interaction of Higher Education and Employers As a Competitiveness Factor of a University
}

\section{Larisa Kapustina ${ }^{1}$, Anna Nosyreva ${ }^{2}$, and Andrei Drevalev ${ }^{1}$}

${ }^{1}$ Ural State University of Economics, Yekaterinburg, Russian Federation

${ }^{2}$ Novouralsk Institute of Technology - branch of NRNU MEPhI, Novouralsk, Russian Federation

\section{Abstract}

The labor market constantly demands qualified personnel and increases the requirements for graduates of educational establishments. In order to train a competitive young professional, universities seek modernization of various kinds and implement it in the educational process. Dual form of education is one of these efforts undertaken by educational institutions. The article presents the results of the semantic analysis of the dual education concept, an analysis of the stakeholders' roles in the system of higher education with a large emphasis on the role of the employer, statistical

Corresponding Author:

Larisa Kapustina

lakapustina@bk.ru

Published: 21 January 2021

Publishing services provided by Knowledge E

(c) Larisa Kapustina et al. This article is distributed under the terms of the Creative Commons Attribution License, which permits unrestricted use and redistribution provided that the original author and source are credited.

Selection and Peer-review under the responsibility of the XXIII International Conference Conference Committee. data collection, and the main advantages and disadvantages of the dual approach to the educational process organization. The aim of the study is to analyze experience of dual education development in Germany, where it is regulated at the legislative level. The main advantages of dual education are identified: establishing practice-oriented training system, involving motivated employers in the training process and educational programs designing, alternating the theoretical and on-the-job training, and reducing the costs associated with personnel selection and adaptation. The study has developed a generalized process model for the implementation of the project "Introduction of the dual form of education in an educational organization". According to the proposed model, the first stage includes developing normative acts regulating dual education training, forming a team of mentors, and selecting students. At the second stage, the authors propose to distribute the contact work as follows: $60 \%$ for theoretical training and $40 \%$ for production-based. The final stage is devoted to the evaluation of the of the dual education system implementation effectiveness. The model was tested for the Novouralsk Institute of Technology - branch of the National Research Nuclear University MEPhl. The study presents a stage-by-stage description of the model and examines examples of the education dual form positive effects at the university, as well as considers emerging "noises".

Keywords: dual education, professional training, educational system.

\section{G OPEN ACCESS}




\section{Introduction}

Transformation of the social and economic development priorities of the territories requires and leads to changes in relations between the business and educational environment. In order to meet new challenges, modern graduates of educational organizations should have not only mastered competencies in accordance with the requirements of the federal state educational standards, but also developed personal qualities that contribute to the formation of a personality of a professional who is flexible and ready for continuous self-improvement and self-development.

An educational organization providing higher education services is not a closed system. In its functions it interacts with the external environment and in particular with consumers of educational services as stakeholders.

Classification of stakeholders at the university activities can be arranged with various approaches. The only priority is the importance of the dialogue between the educational organization and stakeholders: on the one hand, the university provides information; on the other hand, it learns and recognizes the stakeholders' needs and expectations so that it could transform them into the goals and objectives of educational activities.

The employer is given a special role in the classification of stakeholders [2].

The hypothesis of the employer's important role for a higher education organization of is confirmed in various legal regulations and local acts. In particular, establishment of a system for attracting employers to designing educational standards and accreditation of educational programs is identified as one of the target milestones for the development of the education system in the Concept of the long-term social and economic development of the Russian Federation for the period until 2020. This measure is seen as a way to improve the quality of education.

Experts have noted an increasing gap between the level of university graduates training and the requirements for competencies and practical skills set by potential employers. This fact looks especially worrying in the light of the fact that in accordance with the trends in the higher education developments that were identified by the President of the Russian Federation, the aims of Russian universities include entering and improving their positions in various world rankings [3]

It appears logical that the primary work should focus not on the position of the educational institution in the selected rankings, but on improving of the education quality and, as a result, reducing the gap between the expectation of the business environment and the level of a graduate's training. 


\section{Methodology and Methods}

Each educational organization has its own approach to its strategic work aimed at reducing the degree of stakeholders' dissatisfaction with the level of graduates' practical training. As a result, the strategic ways of improving competitiveness and increasing demand for their graduates are different. Educational institutions sign agreements with companies to provide internship (pre-graduation practical training) opportunities to the students, organize course projects and graduation thesis as practical studies in the production environment, etc. At the same time, it appears that introduction of the dual form of education or its elements to the educational process is the most effective and promising way of coordinated interaction between the educational and business environment in the scope of students' training.

\section{Results and Discussions}

The semantic analysis of "dual education" concept allows us to note that the term can be considered in its "narrow" and "broad" meaning [4].

According to the "narrow" definition, which is relevant for this study, dual education is a form of training that combines theoretical education with the development of a student's professional competence at the premises of a partner enterprise.

Germany is the undisputable leader in the organization and introduction of the dual education system, or dual training system. The institute of vocational training is characterized by a widespread implementation of mentoring, and the active participation of industrial cluster of specialists' practice-oriented training. It should be noted that the employer is a party involved and interested not only in the result of the training, but, most importantly, in its content [9].

As opposed to the Russian Federation, Germany strictly regulates the process of dual education by law. According to statistics, more than 600 thousand of the 3.7 million enterprises in Germany take actively part in the implementation of the dual form of education. An important fact is that foreign companies carry out forward planning of their needs in staff, thus, a future student begins his / her career not with the choice of a university for further education, but with finding a partner company that can sign an agreement for further cooperation on the dual form of education [8].

It would be unfair to claim that the dual form of education is unique and implemented only in the German system of education. The system of vocational and technical 
education in the USSR was based on a rational alternation of theoretical and on-the-job training and it also provided the opportunity for continuous training of personnel.

The Center for University Management and Reputation Research has identified twelve intangible assets / values of universities that influence the reputation of an educational institution. The following assets should be highlighted among others: "the quality of the workplace", "practices and internships", "opportunities for employment" [5]. We may note that high scores for these indicators can be achieved with the use of the dual education system, which provides opportunities for the main stakeholders - consumers of educational services, including the following ones [7]:

- from the perspective of the state and society as a whole: reduction of unemployment rate among graduates of educational institutions; improvement of investment and business microclimate in the area, etc.;

- from the perspective of an enterprise - the employer: reduction of the costs associated with searching for, selecting and adapting employees; possibility of training and bringing up personnel with specific consideration of the production peculiarities, etc.;

- from the student's perspective: improvement of practical skills increases competitiveness in the labor market and, as a result, increasing chance of employment; increasing motivation to learn and put complex theories into practice and master skills by solving real production tasks, etc.;

- from the perspective of an educational institution: meeting performance indicators of state monitoring; ensuring compliance of the teachers' professional training with the corresponding level of technical equipment of the production process; providing innovative training aids and equipment, etc.

Despite the clear advantages of the dual education introduction, it is also associated with a number of difficulties:

- insufficient elaboration and documentation on the matter of implementing the dual form of education in the Russian Federation at the legislative level;

- low interest in admission of students on a dual form education among managers of industrial enterprises attributed to the prolonged effect of this method of staff selection;

- possibility of information "noise" in the dialogue between an educational organization and the production sector in the process of negotiating the content of the educational program, etc. [6] 
As it was noted, one of the unfavorable factors for implementation of dual form of education and its replication and scaling up from pilot projects to universities is the multivariance of methodological recommendations and the lack of a general process model for introducing a dual form of education [1]. Figure 1 presents the process model of the dual form of education introduction.
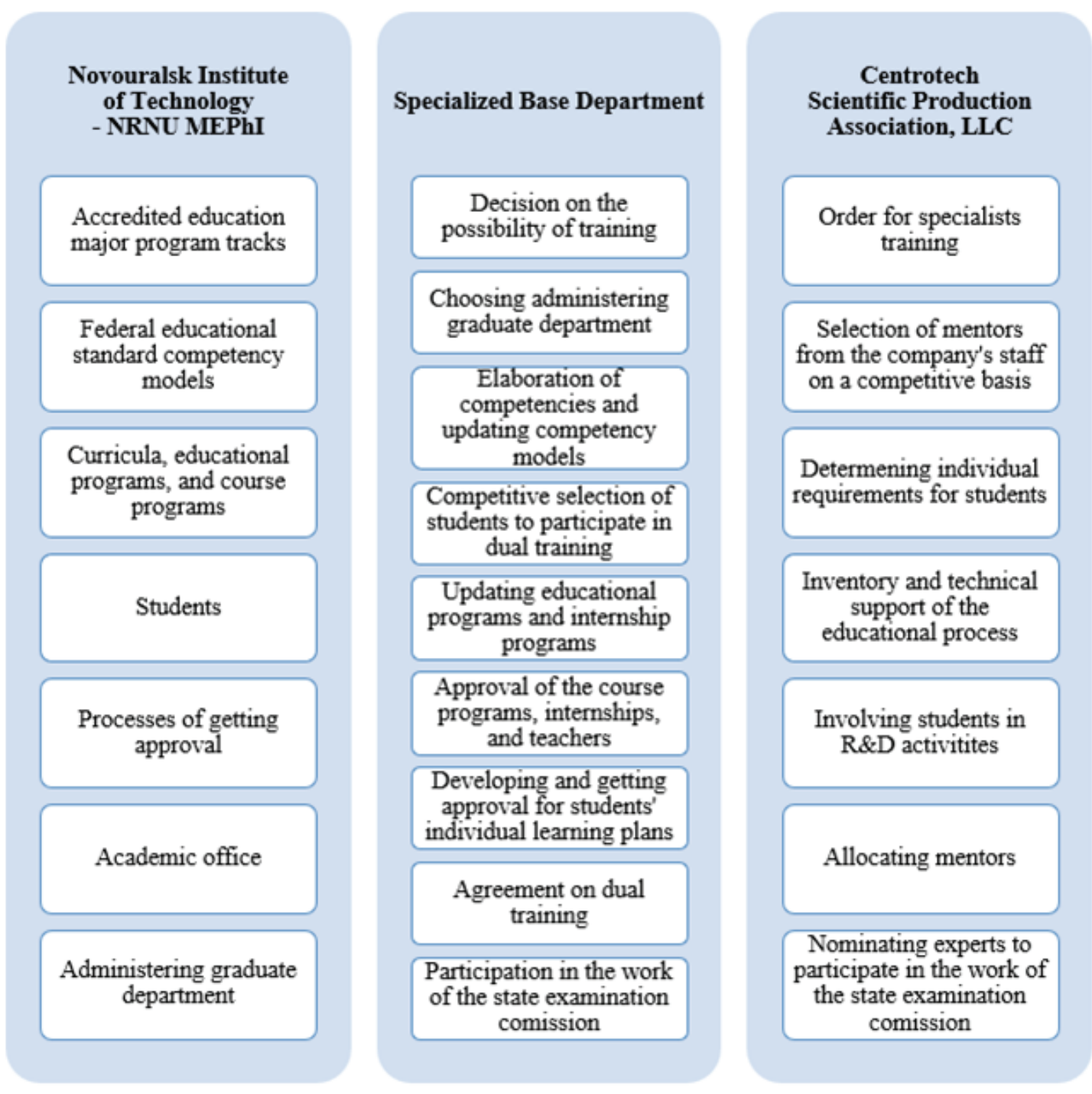

Figure 1: General model of the dual education introduction process (Authors' own elaboration)

According to the model, the work is assumed to be divided into three stages: preparation, implementation and analysis.

At the preparation stage, an important role is given to the selection of personnel at the enterprise and in the university to create various working groups, as well as a joint working group, which is responsible for the following tasks:

- elaborating and drafting normative local acts regulating the process of dual education; 
- forming the team of mentors;

- developing students' selection procedure for the dual for of education.

The stage of the process implementation, according to the model, provides for the distribution of the total amount of work in contact with students: at least $60 \%$ is allocated to theoretical training.

Last but not least, the final stage is the implemented dual education system effectiveness analysis. Applicable tools include testing students to determine the degree of acquired professional competencies, as well as analyzy the compliance of the obtained results with expectations of the all parties taking part in the implementation of the dual form of education.

\section{Results}

The dual education project has been implemented by the Novouralsk Institute of Technology - NRNU MEPhl in cooperation with Centrotech Scientific Production Association, LLC since 2018.

\section{Conclusions}

The project "Introduction of the dual form of education at the NTI NRNU MEPhl", in the scope of its implementation, has got positive conclusions and also provided insights on the 'noise' factors that reduce effectiveness of introducing such a form of educational process organization.

The positive conclusions on the project include the following factors that are worth noting:

- representatives of the partner enterprise took an active part in the development of the educational program and thus, contributed to the practice-oriented training of students; as a result, graduates' competitiveness in the labor market has increased;

- the partner enterprise has improved the qualitative and quantitative aspects of the process of forecasting the need for personnel, which has allowed to form an application for employer-funded education;

- introduction of the dual form of education contributed to the improvement of pedagogical technologies used in the educational process, the methodological base was updated; 
- in the scope of practical work at the enterprise, students adapted to corporate culture and ethics, shared the company values;

- the human resources department of the enterprise acted as the supervisor of the process and could "impose a filter" for the students' further employment as it got prior practical information about their strengths and weaknesses.

Despite significant positive feedback, there were a number of factors that put the process out of balance. The following factors influenced the management of the dual form of education:

- formal and sceptical attitude of the partner enterprise employees towards participation in the dual education system. Underdeveloped mentoring does not facilitate the process of establishing the "university-enterprise-mentor-student" relationship;

- a certain degree of transformation was required from the professors and faculty of the educational organization (improving their own skills and the quality of knowledge, readiness to change the existing training system, etc.).

It should be noted that by establishing education process with introduction of the dual education elements, both a university and stakeholders obtain a number of advantages. This form of education has not been duly enshrined in the educational legislation of the Russian Federation so far, but it has proved its practical significance.

\section{References}

[1] Burlyaeva, V. A., Burkina, I. V., Bulakh, K. V. and Chebanov, K. A. (2018). The specifics of construction of models of implementation of dual education (learning) at the regional level. The world of science, culture and education, vol. 6, issue 73, pp. 349-351.

[2] Gayete, M. (2019). Reputation - is not a product that can be made, but a fruit that needs to be grown. Accreditation in Education, vol. 7, issue 115, pp. 18-23.

[3] Kapustina, L. M., Jadko, E. A., Izakova, N. B. and Yakimenko, E. V. (2016). Market research of education's quality in the university as indicator of human well-being. In: The European Proceedings of Social \& Behavioural Sciences EpSBS Volume XIX, Proceedings of the III International Scientific Symposium "Lifelong wellbeing in the world". Tomsk Polytechnic University, Tomsk, Russia, pp. 714-721. 
[4] Kutumova, A. A. and Yarkova, G. A. (2016). Dual educational system as a training technology of bachelors' of vocational education in the pedagogical institution of today. Modern high technologies, vol. 4-1, pp. 139-142.

[5] Nekrasov, S. I., Zakharchenko, L. V. and Nekrasov, Y. A. (2015). Pilot project "Dual teaching": specialists' a critical view. Vocational education. Capital, vol. 4, pp. 9-16.

[6] Rodikov, A. S. (2010). Some aspects of the profiling of educational services of the dual system of European education. Bulletin of the Military University, vol. 3, issue 23, pp. 41-46.

[7] Shauro, E. V. (2015). Dual teaching: experience of participation in a pilot project. Vocational Education. Capital, vol. 5, pp. 43-45.

[8] Sidakova, L. V. (2016). The essence and main features of the dual teaching model. Education and upbringing, vol. 2, pp. 62-64.

[9] Tidemann, B. (2011). The dual system - the German form of vocational education. Education and Science, vol. 6, pp. 112-123. 